\title{
Exceptionally Active Yttrium-Salen Complexes for the Catalyzed Ring Opening of Epoxides by TMSCN and $\mathrm{TMSN}_{3}$
}

\author{
Biswajit Saha, Mei-Huey Lin and T.V. RajanBabu \\ Department of Chemistry, 100 W. $18^{\text {th }}$ Avenue, The Ohio State University, Columbus, Ohio 43210
}

\section{Table of Contents}

$\begin{array}{lrl}\text { General methods } & \text { S2 }\end{array}$

$\begin{array}{ll}\text { Details of the kinetic experiments } & \text { S2 }\end{array}$

$\begin{array}{ll}\text { Gas chromatograms showing separation of enantiomers } & \text { S6 }\end{array}$

Probing Non-linear Effects (graph of \%ee of catalyst vs \%ee of the products) S13

$\begin{array}{lr}\text { Table 1. Crystallographic details for } 6 & \text { S14 }\end{array}$

$\begin{array}{lr}\text { ORTEP Representation of } 6 & \text { S15 }\end{array}$ 


\section{Supporting Information}

General Methods. All catalyzed reactions were carried out under an inert atmosphere of nitrogen in a Vacuum Atmosphere drybox, or by Schlenk techniques. Methylene chloride $\left(\mathrm{CH}_{2} \mathrm{Cl}_{2}\right)$ was distilled from calcium hydride under nitrogen and stored over molecular sieves. Tetrahydrofuran (THF) was distilled from sodium benzophenone ketyl under nitrogen and stored over molecular sieves. Hexane was distilled from $\mathrm{CaH}_{2}$ and stored over molecular sieves. All chemicals were purchased from Aldrich Chemical Company unless otherwise noted. Analytical TLC was done on precoated $(0.25 \mathrm{~mm})$ silica gel $60 \mathrm{~F}_{254}$ plates. Column chromatography was conducted by using silica gel 40 . Gas chromatographic analyses were performed on a 1 cross-linked methyl silicon capillary column (25 m length $\times 0.2 \mathrm{~mm}$ i.d.) and an FID detector connected to a digital integrator. Gas chromatographic separations of enantiomeric products from the meso epoxides were accomplished using Cyclodex-B or Chiraldex B-Ph capillary GC columns. As carrier gas helium was used. In all cases, a base-line separation of the relevant components was observed (see later for typical chromatograms). Optical rotations were recorded in solution at the sodium D-line in chloroform. Yttrium salt, $\mathrm{Y}\left[\mathrm{N}\left(\mathrm{SiMe}_{2} \mathrm{H}_{2}\right]_{3} .2 \mathrm{THF}\right.$ and complexes $\left[\mathbf{L}_{\mathbf{1}}-\mathbf{L}_{\mathbf{7}}\right] \mathrm{Y}\left[\mathrm{N}\left(\mathrm{HSiMe}_{2}\right)_{2}\right][\mathrm{THF}]$, scandium salt $\mathrm{Sc}\left[\mathrm{N}\left(\mathrm{SiMe}_{2} \mathrm{H}\right)_{2}\right]_{3}$. THF and complex $\left[\mathbf{L}_{4}\right] \mathrm{Sc}\left[\mathrm{N}(\mathrm{HSiMe})_{2}\right][\mathrm{THF}]$ were prepared according to the literature procedure as published by us before (Lin, M. -H.; RajanBabu, T. V. Org. Lett. 2002, 4, 1607.). Kinetics study was performed using a ASI react-IR ${ }^{\circledR} 1000$ Reaction Analysis System. Details of the Kinetic Experiments. A typical kinetic experiment was run as follows with TMSCN as the limiting reagent with excess of the epoxide. To a mixture of the epoxide $(0.250 \mathrm{~g}, 0.257 \mathrm{~mL}, 2.5$ $\mathrm{mmol})$ and the catalyst $\left[\mathbf{L}_{4}\right] \mathrm{Y}\left[\mathrm{N}(\mathrm{dms})_{2}\right][\mathrm{THF}](0.005 \mathrm{~g}, 0.005 \mathrm{mmol})$ in $0.5 \mathrm{~mL}$ of hexane, under nitrogen, was added $5 \mu \mathrm{L}(0.000038 \mathrm{mmol})$ of TMSCN and the mixture was stirred for 30 minutes. The ReactIR ${ }^{\circledR}$ probe was introduced, and the mixture was cooled to $0{ }^{\circ} \mathrm{C}$ in an ice bath where the 
temperature was rigorously maintained $\left( \pm 0.1^{\circ} \mathrm{C}\right)$ through out the experiment. After equilibration, $\operatorname{TMSCN}(0.05 \mathrm{~g}, 0.067 \mathrm{~mL}, 0.5 \mathrm{mmol})$ was added and the spectra were collected at 1 min intervals.

Kinetic runs were carried out with different concentrations of the catalyst, in a 10-fold range, between with 0.1 to $1 \mathrm{~mol} \%$, with respect to TMSCN. For the higher concentrations of the catalyst $(0.0060 \mathrm{M}$ and $0.0045 \mathrm{M})$ only the data for $4 \mathrm{~min}$ and $5 \mathrm{~min}$ corresponding to $62 \%$ and $50 \%$ conversion respectively are used. Plots of $\ln \left[\left(a^{0}\right) /\left(a^{0}-x\right)\right]$ versus time $(\min )$, where $\left(a^{o}\right)$ is the initial absorbance of (TMSCN) and $\left(\mathrm{a}^{\mathrm{o}}-\mathrm{x}\right)$ is the absorbance of remaining TMSCN as measured by the absorbance at time t] gives straight lines (Figure 1), indicting a first order reaction under these conditions. The relative values of $\mathrm{k}_{\mathrm{obs}}$ were derived from the slope of these lines and, they are tabulated, in Table 1, against the various individual concentrations of the catalyst.

\section{$t$ in $\min v s \ln (\mathrm{aO} / \mathrm{aO}-\mathrm{x})$}

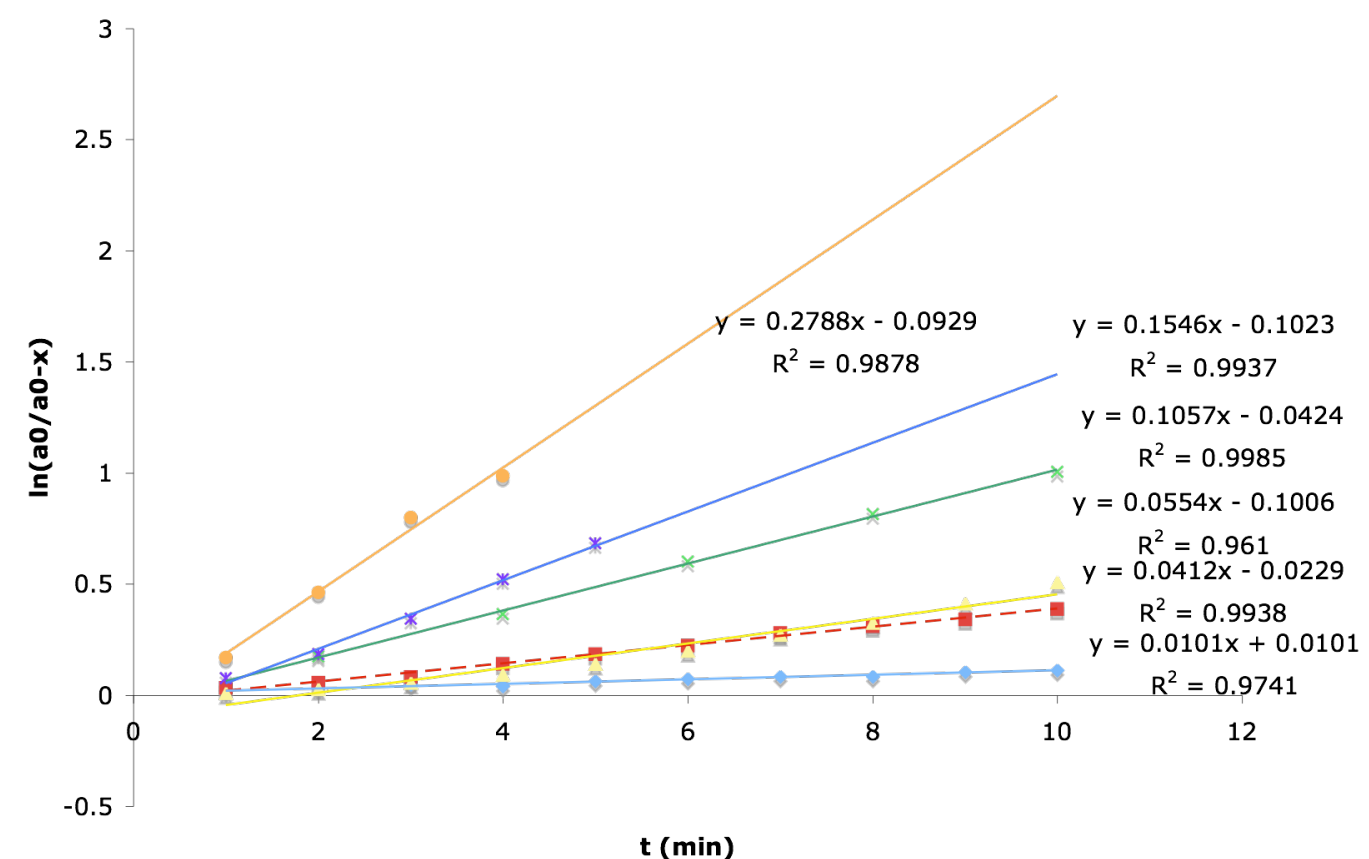

Figure 1. Plot of $\ln \left[\left(\mathrm{a}^{0}\right) /\left(\mathrm{a}^{\mathrm{o}}-\mathrm{x}\right)\right]$ vs $\mathrm{t}(\mathrm{min})$ at Concentrations of the Catalyst between $0.00061 \mathrm{M}$ and $0.0060 \mathrm{M}$ 
Table 1. Catalyst Concentration vs $\mathrm{k}_{\mathrm{obs}}\left(\mathrm{min}^{-1}\right)$

\begin{tabular}{|l|l|l|l|}
\hline entry & {$[$ cat $] \mathrm{M}$} & {$[\mathrm{cat}]^{2} \times 10^{7}$} & $\mathrm{k}_{\mathrm{obs}}$ \\
\hline 1. & 0.00061 & 3.721 & 0.0101 \\
\hline 2. & 0.00152 & 23.104 & 0.0412 \\
\hline 3. & 0.00212 & 44.944 & 0.0554 \\
\hline 4. & 0.00303 & 91.809 & 0.1057 \\
\hline 5. & 0.00454 & 206.120 & 0.1546 \\
\hline 6. & 0.00600 & 360.000 & 0.2788 \\
\hline
\end{tabular}


Figure 2. Plot of (a) $\mathrm{k}_{\mathrm{obs}}$ vs [cat. concentration] ${ }^{2}$ and (b) $\mathrm{k}_{\mathrm{obs}} \mathrm{vs}$ [cat. concentration] 
A plot of $\mathrm{k}_{\mathrm{obs}}$ vs [cat] ${ }^{2}$ and $\mathrm{k}_{\mathrm{obs}} \mathrm{vs}$ [cat], shown in Figures $2 \mathrm{a}$ and $2 \mathrm{~b}$, gave inconclusive results with $\mathrm{R}^{2}$ values of 0.995 for the former, and 0.961 for the latter. We believe that this data does not permit determination of an order with respect to the metallic reagent, even though very similar data $\left(\mathrm{R}^{2}=\right.$ 0.997 and 0.967 respectively) was used by Jacobsen (Schaus, S. E.; Jacobsen, E. N. Org. Lett. 2000, 2, 1001.) to argue in favor of a bimetallic activation process in the (pybox) $\mathrm{YbCl}_{3}$-mediated epoxide opening by TMSCN. 


\section{Gas Chromatographic Analysis of the Epoxide Opening Products}
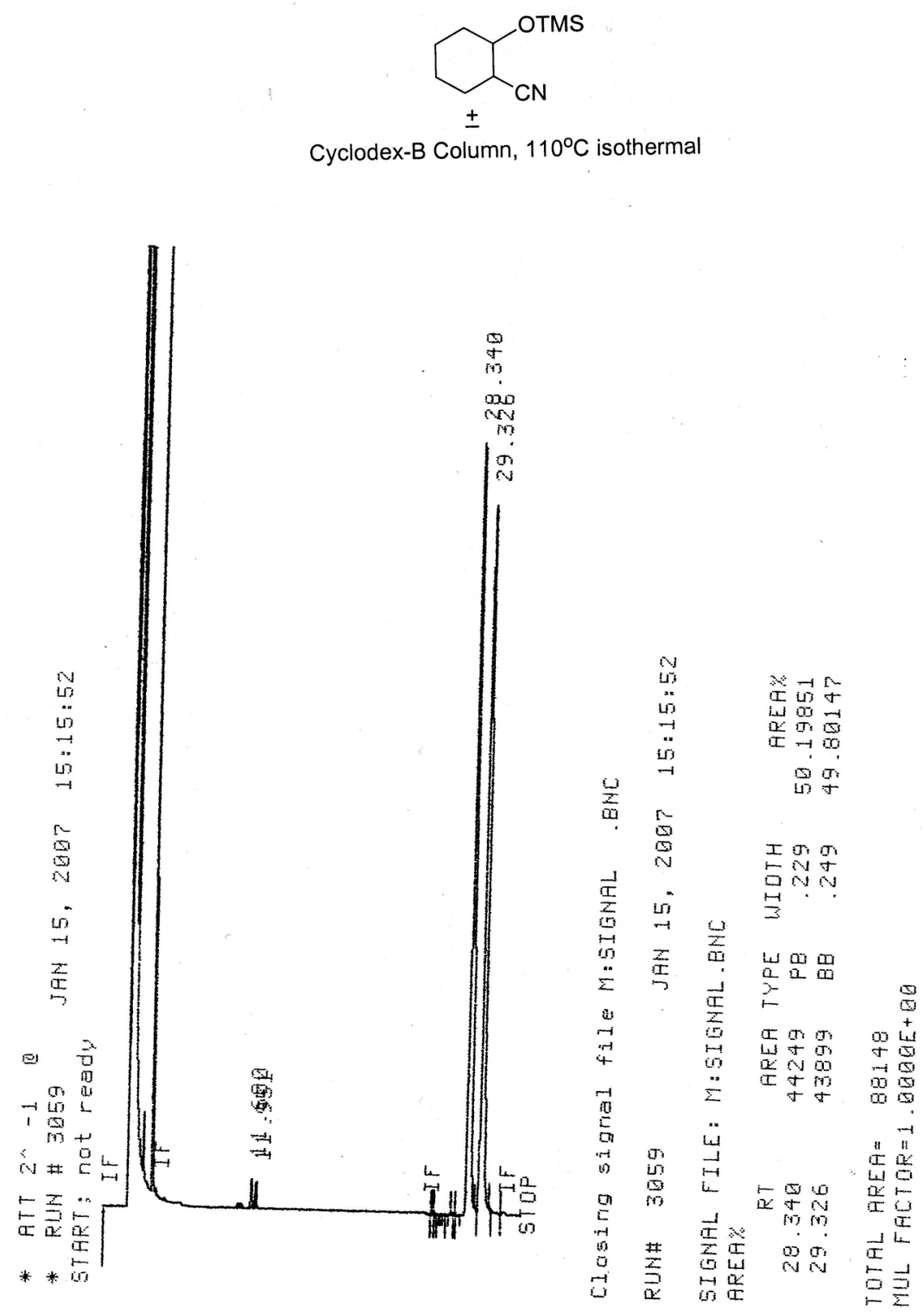







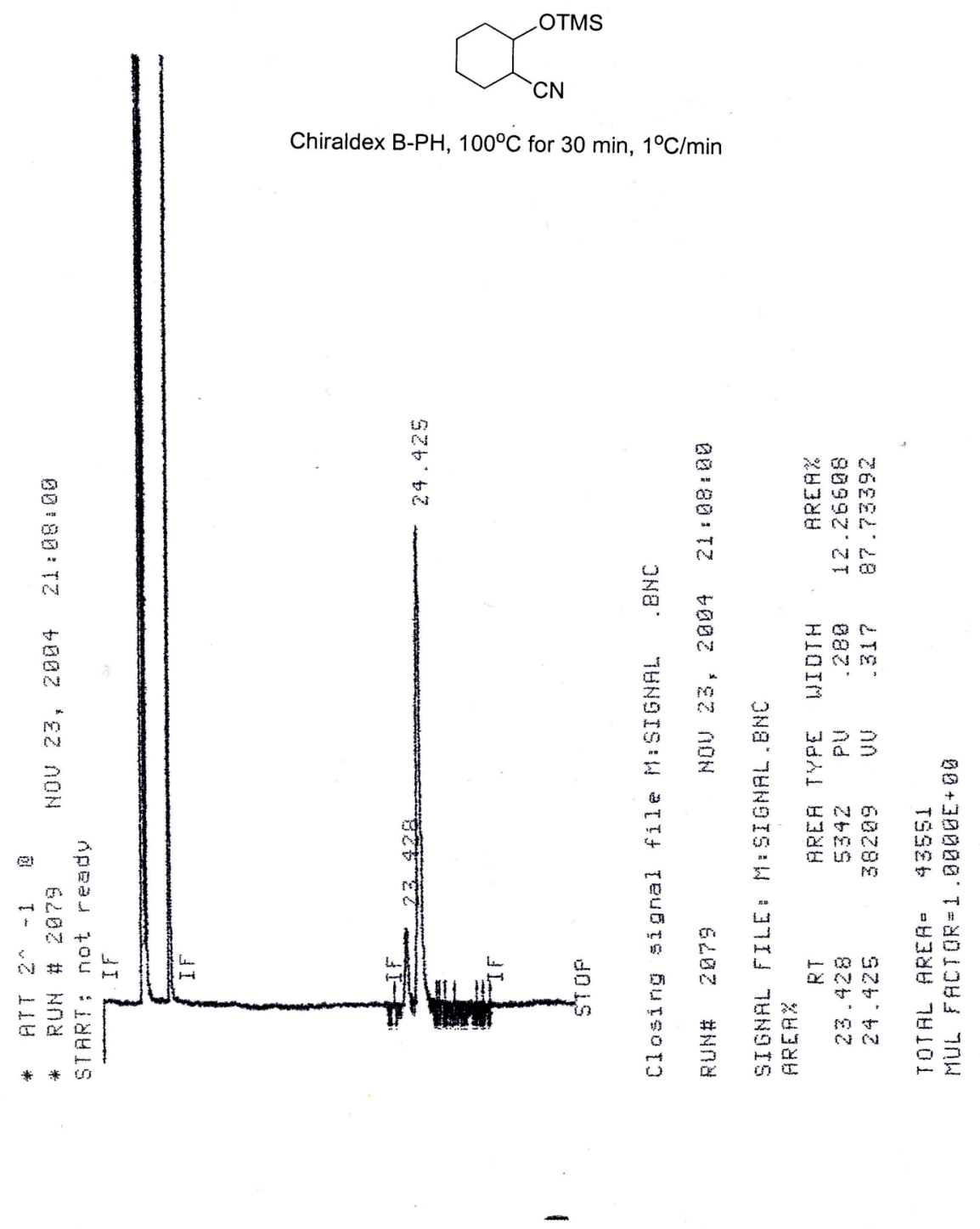




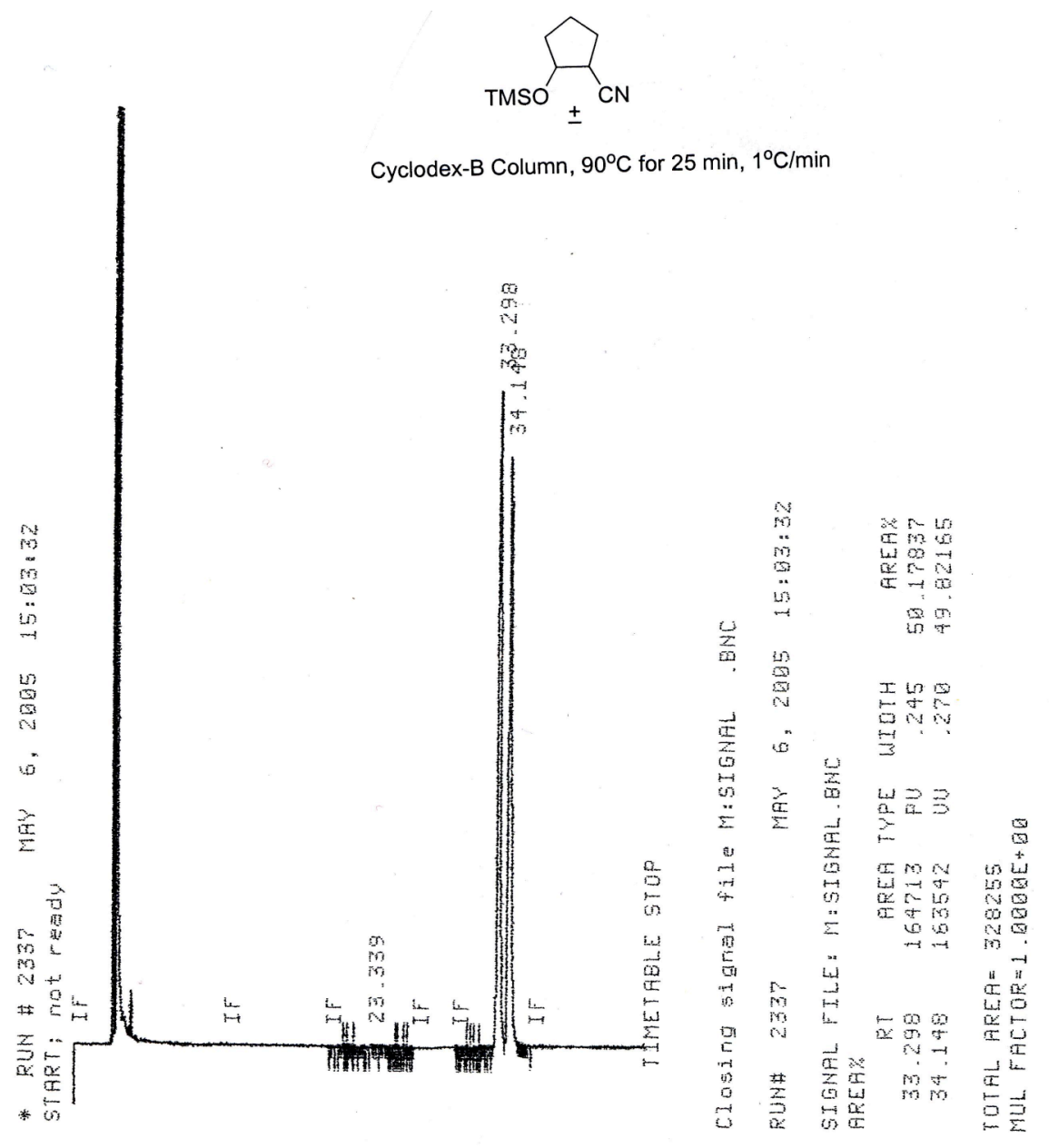




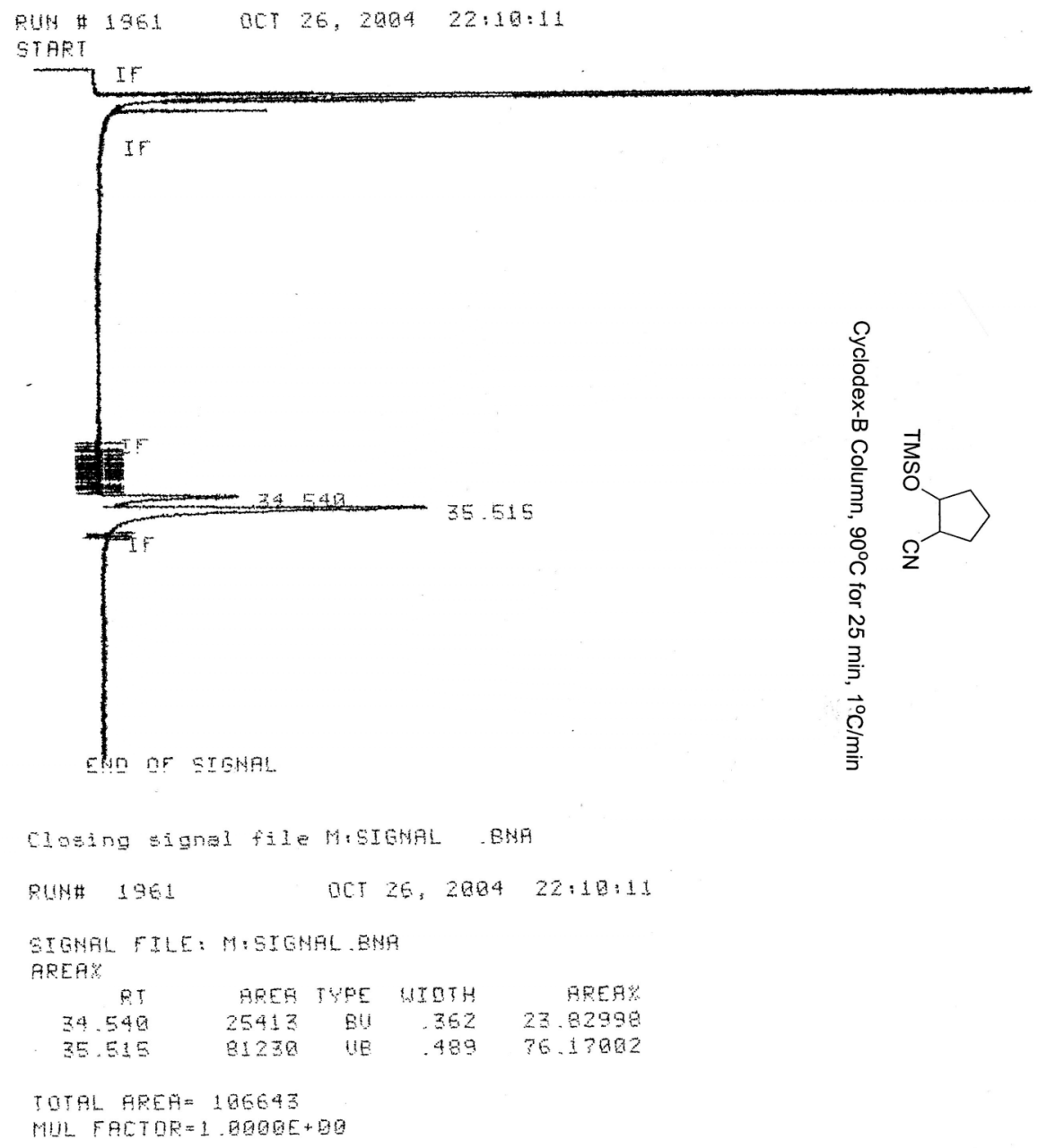




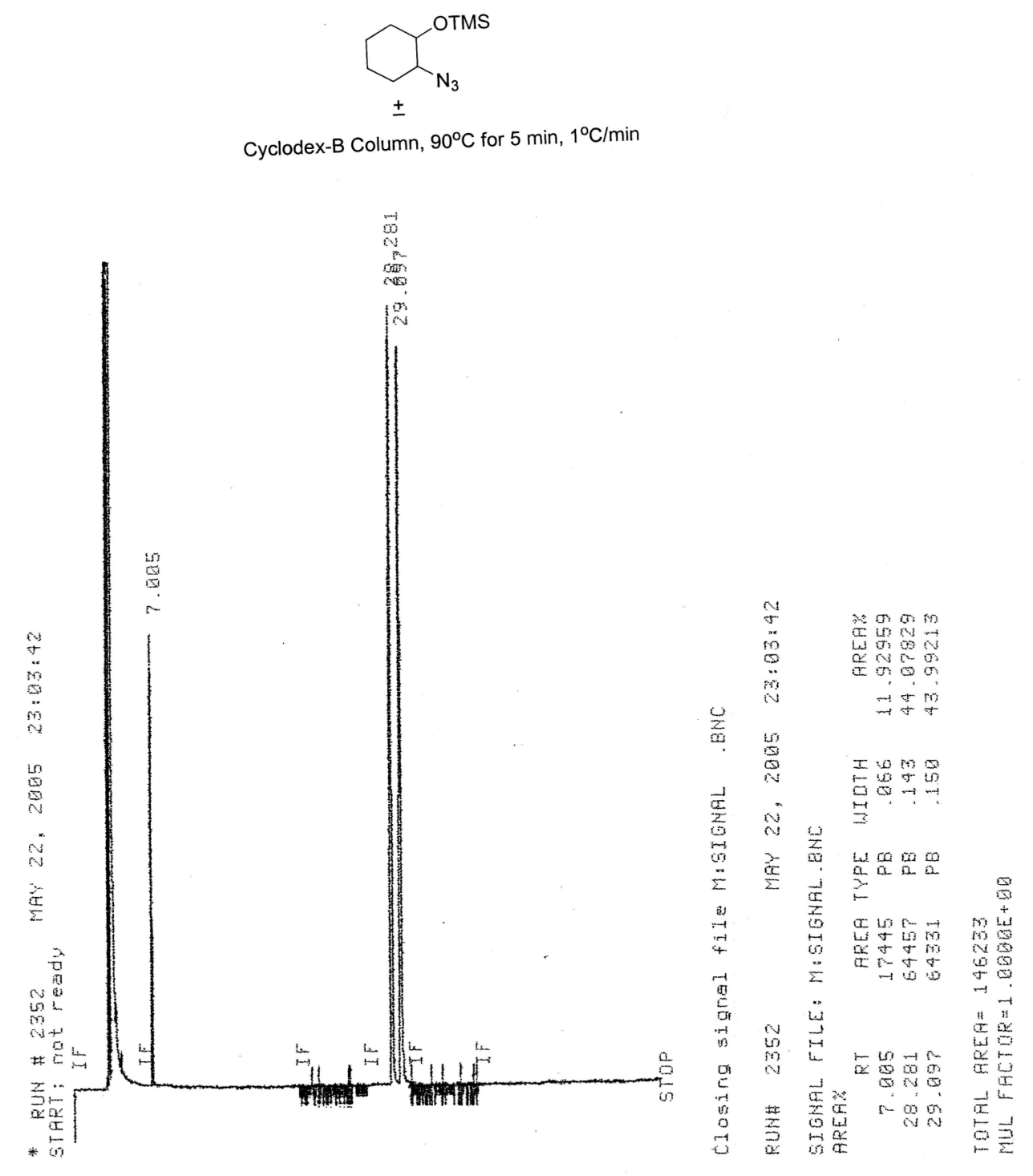




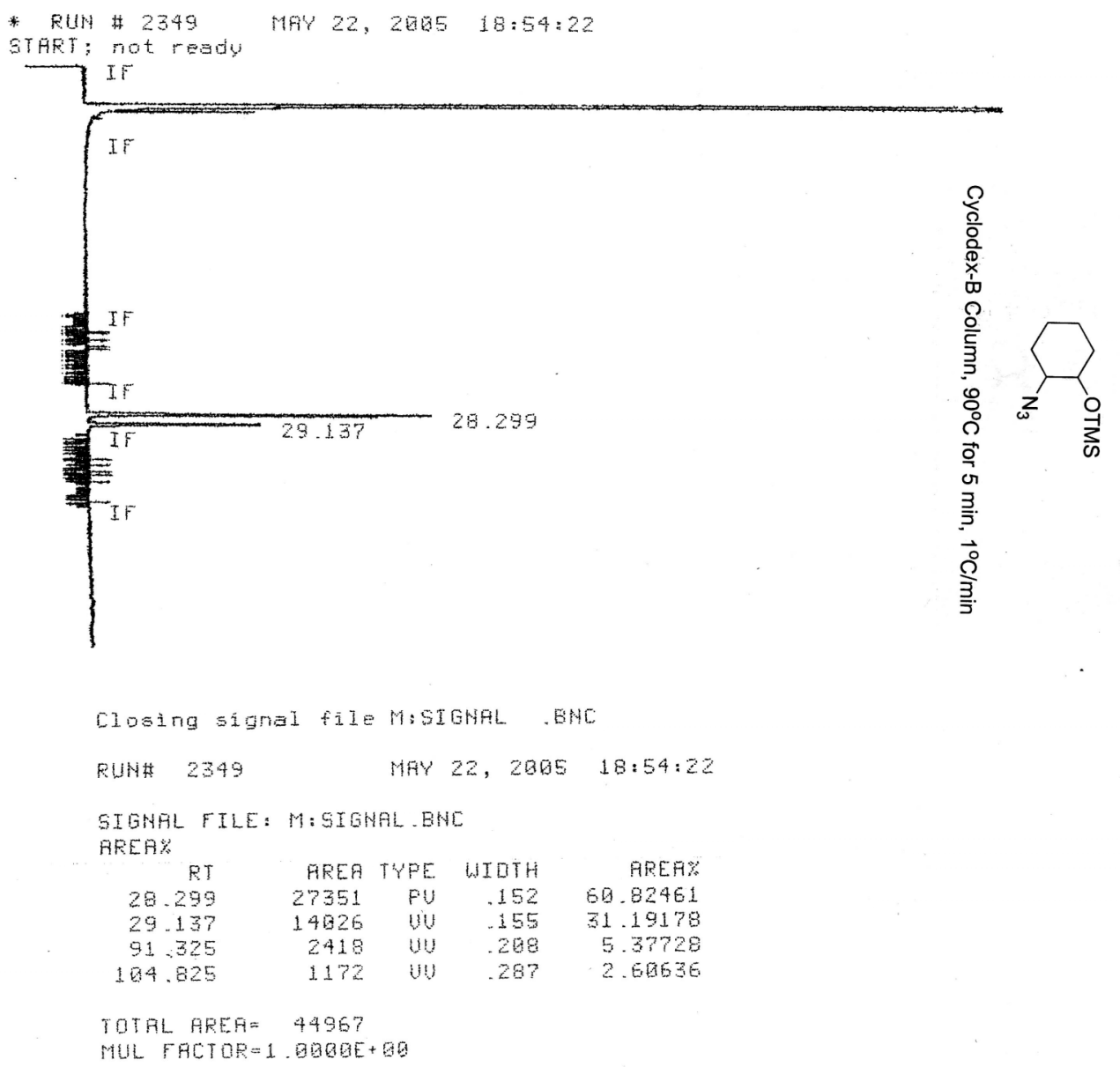




\section{Probing the Non-linear Effect}

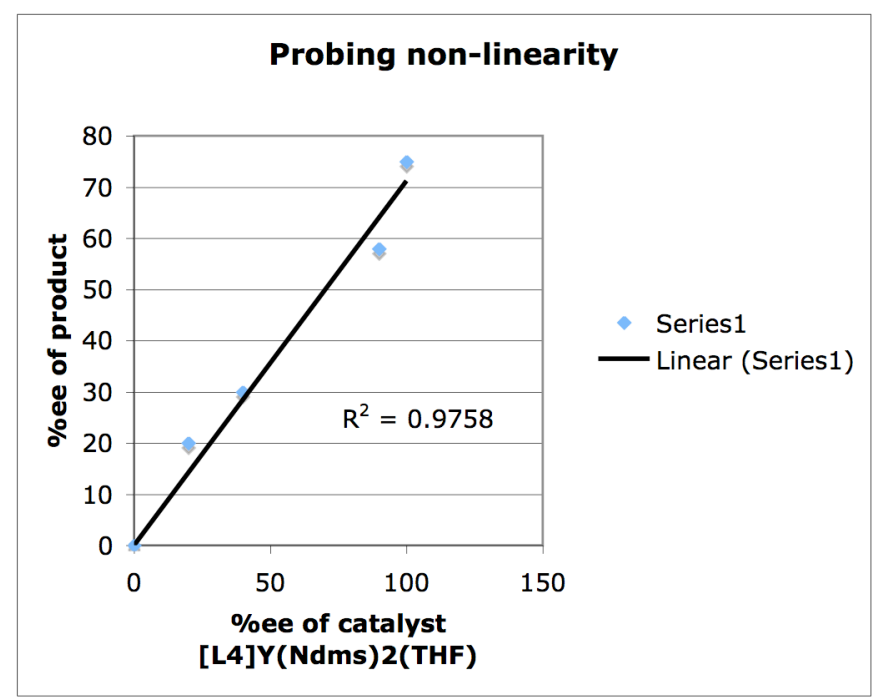


Table 1. Crystallographic details for 6

\begin{tabular}{|c|c|}
\hline Empirical formula & C100 H108 N4 O6 Y2 + 1.5 (C5 H12) \\
\hline Formula weight & 1747.94 \\
\hline Temperature & $150(2) \mathrm{K}$ \\
\hline Wavelength & $0.71073 \AA$ \\
\hline Crystal system & orthorhombic \\
\hline Space group & $\mathrm{P} 2{ }_{1} 2_{1} 2_{1}$ \\
\hline \multirow[t]{3}{*}{ Unit cell dimensions } & $a=17.979(2) \AA$ \\
\hline & $\mathrm{b}=19.295(3) \AA$ \\
\hline & $c=30.509(5) \AA$ \\
\hline Volume & $10583.7(3) \AA^{3}$ \\
\hline Z & 4 \\
\hline Density (calculated) & $1.097 \mathrm{Mg} / \mathrm{m}^{3}$ \\
\hline Absorption coefficient & $1.141 \mathrm{~mm}^{-1}$ \\
\hline $\mathrm{F}(000)$ & 3700 \\
\hline Crystal size & $0.19 \times 0.23 \times 0.38 \mathrm{~mm}^{3}$ \\
\hline Theta range for data collection & 2.04 to $24.98^{\circ}$ \\
\hline Index ranges & $-21<=\mathrm{h}<=21,-22<=\mathrm{k}<=22,-36<=1<=36$ \\
\hline Reflections collected & 79409 \\
\hline Independent reflections & $18343[\mathrm{R}($ int $)=0.080]$ \\
\hline Completeness to theta $=24.98^{\circ}$ & $99.8 \%$ \\
\hline Refinement method & Full-matrix least-squares on $\mathrm{F}^{2}$ \\
\hline Data / restraints / parameters & $18343 / 42$ / 1069 \\
\hline Goodness-of-fit on $\mathrm{F}^{2}$ & 1.091 \\
\hline Final $\mathrm{R}$ indices $[\mathrm{I}>2 \operatorname{sigma}(\mathrm{I})]$ & $\mathrm{R} 1=0.0697, \mathrm{wR} 2=0.1877$ \\
\hline $\mathrm{R}$ indices (all data) & $\mathrm{R} 1=0.0803, \mathrm{wR} 2=0.1923$ \\
\hline Absolute structure parameter & $0.068(7)$ \\
\hline Largest diff. peak and hole & 1.675 and $-0.571 \mathrm{e} / \AA^{3}$ \\
\hline
\end{tabular}






The Thermal Ellipsoid Figure for $6\{[\mathbf{L} 4] \mathrm{Y}(\mathrm{u}-\mathrm{OH})\}_{2}$ 